\title{
Interventions for sexually abused children - a mismatch between evidence and practice is harmful to children
}

\author{
Vajira Dharmawardene
}

Unlike other forms of child maltreatment, sexual abuse tends to receive more attention from media, public and clinicians. One reason for this disproportionate attention is the belief that sexual abuse causes more negative effects compared to other forms of child maltreatment. Interventions for child maltreatment appear to be based on this rationale as well.

Negative effects associated with sexual abuse in childhood are well known and multiple; including emotional and behavioural problems, self-harm behaviours, substance misuse, aggression, low self-esteem, academic problems, and problems in sexuality(1).These could manifest at any time in the life of the affected individual.

However recent studies have shown that sexual abuse may not be the form of child maltreatment that has most deleterious effects on children. Verbal victimization and bullying of children could be associated with more psychological effects than isolated incidents of sexual abuse (2). Research consistently suggests that, while the effects of sexual abuse are extremely variable, most victims do not experience long-term impairment. It is difficult to demonstrate that any particular treatment is more effective than just passage of time (3).

Another area of controversy is in delineating the effect of child maltreatment is establishment of direction of causality. It is not always clear whether the effects could be singled out to a single event as many abuse incidents are associated with enduring family/social dysfunction(4).

When prevention of negative effects is the goal, it is important to include these considerations into practice. For example is it fair to not to intervene when verbal abuse and childhood bullying is the form of maltreatment and employ all resources to prevent child sexual abuse? Vocal opinions held by stakeholders in this field are not compatible with what we know from research. Are we seeing a reversed application of Victorian morality, based on thinking of selected parties involved in agenda setting in the field of child maltreatment?

Some actions, though well intended, are probably of minimal effectiveness in achieving the stated goal of preventing harms of child maltreatment. Conversely, some could be actually causing harm to the children and the families affected.

The role of the psychiatrist is one such example. Some stakeholders believe that psychiatrists have a fundamental role in prevention of negative effects of child maltreatment. They believe children are hugely "traumatised" by any act of sexual abuse and all affected children need "counselling" or mental health intervention. This has resulted in even children as young as 5 years being taken to a psychiatrist for "counselling" and assessment in busy psychiatric clinics, where severely mentally ill also come for treatment. This procedure traumatizes the child more than the alleged act of sexual abuse. The main issue bothering the child at the assessment is not the act of sexual abuse, but whether after all drama, he/she would be able to return to the same school to study the following day. It is highly probable the child would be ostracised by teachers and friends on his/her return.

This procedure is carried out as if it is a legal requirement, often without the informed consent of either the child and/or the guardian. It amounts to further victimisation of the child and family.

To address the issue of child sexual abuse effectively, it is essential to place it primarily as a public health issue (and a criminal act), not as a mental health problem, though there could be a proportion of children who are psychologically affected.

Child sexual abuse has a broad definition in most jurisdictions. In its broadest sense, it could be defined as an activity between a child and an adult person intended to gratify or satisfy the needs of the adult person. It is considered an inherently violent act, regardless of the use of physical force or resulting contact or injury (5). Child sexual abuse includes a wide range of actions, not mere penetrative sex. Broadly, they are contact and noncontact sexual abuse. Contact abuse could be penetrative or non-penetrative. Exposing one's genitals to children or inducing them for sex is sexual abuse. Using a child for pornography is also sexual abuse.

It is important to realise that with this definition, physical evidence like in the event of rape or demonstrable 
psychological harm is not required for the conviction of child sexual abuse. Producing a young child for psychiatric assessment by Police/Judicial Medical Officer for being shown a pornographic video clip by an adult is often unnecessary and confuses the child and their parents/guardians.

It is known that only about 10 per cent of child sexual incidents get reported and most sexual abusers are well known to the child being abused (5). They may be relatives, family friends, neighbours or people entrusted to look after the children. About one-third of abusers are related to the child. Most of them are men. Contrary to the popular beliefs based on media reports of sensational cases, most acts involve kissing or genital touching. Force or violence is rarely used and injuries are caused only to a minority of children. Often children do not understand the act as abuse though some realise that it is something that should not have happened, given the secretive behaviour of the perpetrator.

Effective interventions to prevent occurrence and further harm after child sexual abuse need to consider the ecology of child sexual abuse. Most of the child victims of sexual abuse come from families with multiple and complex problems in which multiple adverse circumstances and events are almost a daily occurrence (4). Poverty, unemployment, poor housing or homelessness, lack of access to adequately resourced schools, lack of social support and family dysfunctions including parental alcohol and substance use are commonly encountered in these settings.

It needs no emphasis that these have serious effects on children, and diminish their sense of safety and resilience. It is unlikely a psychiatric assessment alone could lead to interventions required in the social sphere of these children. A tendency could be seen to ignore more vital psychosocial interventions once the referral is made to a psychiatrist first. There are situations where a psychiatric assessment is clearly indicated; for assessment of mental age in children with learning disability, assessment for behavioural changes or changes in functioning level following the event, assessment for known psychiatric illness are such examples.

It is, however, not clear the legal relevance of this practice maintained in every case of child sexual abuse, victimising the child. On occasions, a sexual abuse had not occurred but referral has come for assessment and "counselling"! Some referrals had been initiated just because someone had called on the Police Crisis Line. On other occasions, abuse had been attempted, but not been committed. It is clear that the common sense was not intact when the referrals were made for psychiatric assessment.
Any practice by medical profession should be beneficial and the primaryethicaldutyis not to doany harm. Referring all victims, especially children for psychiatric evaluation, further traumatizes them and undermines their resilience. It is well known the outcome of sexual abuse is heavily influenced by the living environment of the child. Positive social support from family and friends facilitates victim's return to normal life. Empathic, legal, medical and child protection services offer assistance in reducing distress without blaming the victim or the family. However, a significant proportion of children are not fortunate to receive them.

There are staff members, specifically entrusted with the task of offering psychosocial support to children affected by sexual abuse, manning all the divisional secretariats and provincial secretariats in Sri Lanka. It could be argued that they are better placed than psychiatrists to address the complex issues faced by these children. These officers could see the affected children first and refer the children for psychiatric assessment, only when they feel it as necessary. This is more appropriate than referring all for psychiatric assessments.

Some forensic experts are of the view that it is difficult to locate the relevant staff members at divisional secretariats and provincial secretariats so that the children and families get lost in the process. It is sometimes difficult to understand the individual roles of multitude of officers tasked with the role of child welfare. If these responsible officers could be allocated with a specific place and a time in hospitals, where these children are commonly referred to, many psychosocial issues could be addressed.

Though researches have shown sexual abuse is associated with mental health issues in the perpetrator and some time in parents of affected children, they are rarely presented for assessment indicating inadequate processing of the child sexual abuse events. Intervention made on such individuals could be expected to have significant effects on the future perpetration sexual abuse.

This is no way to suggest that the serious crime of child abuse should go unpunished. The legal procedures should follow against perpetrators to deter them for repeating the act, though only a minority (about 13\%) repeats the act.

Child protection actions are often driven by media attention to individual child tragedies, but such reactive steps do not yield a balanced and flexible system for protecting children. Child-rescue impulses must be first tempered by a commitment to do no further harm (6). 
It is time that a comprehensive practice guideline is formulated by considering the views of all stakeholders involved, including forensic and legal experts and mental health professionals on progression of sexually abused children in the forensic and health sectors.

\section{References}

1. Kendall-Tackett, K.A., Williams, L.M., and Finkelhor, D. Impact of sexual abuse on children: A review and synthesis of recent empirical studies. Psychological Bulletin, (1993) 113:164-80.

2. Teicher MH, Samson JA, Polcari A, McGreenery CE. Sticks, stones, and hurtful words: relative effects of various forms of childhood maltreatment. American Journal of Psychiatry, 2006 Jun; 163(6):993-1000.
3. Beutler LE, Rebecca LE, E. Williams E, Zetzer HA. Efficacy of Treatment for Victims of Child Sexual Abuse. The Future of Children, Sexual Abuse of Children, Vol. 4 • No. 2 -Summer/Fall 1994

4. Perez-Fuentes $\mathrm{G}$, Olfson $\mathrm{M}$, Villegas $\mathrm{L}$, et al. Prevalence and correlates of child sexual abuse: a national study. Comprehensive Psychiatry, 2013; 54(1):16-27.

5. Murray LK, Nguyen A, MA, Cohen JA. Child Sexual Abuse. Child and Adolescent Psychiatric Clinics North America. 2014 April ; 23(2): 321-337

6. Scott DA. The landscape of child maltreatment Lancet, 373, 2009 January 10,101-102 